\title{
Methylation-induced silencing of miR-34a enhances chemoresistance by directly upregulating ATG4B-induced autophagy through AMPK/mTOR pathway in prostate cancer
}

\author{
HAIQIU LIAO $^{1}$, YANG XIAO ${ }^{2}$, YINGBIN HU ${ }^{3}$, YANGMING XIAO ${ }^{1}$, ZHAOFA YIN $^{1}$, \\ LIANG LIU ${ }^{4}$, XIAOPENG KANG ${ }^{1}$ and YONGGANG CHEN ${ }^{1}$
}

\author{
Departments of ${ }^{1}$ Urology and ${ }^{2}$ Orthopaedics, Loudi Central Hospital of Hunan Province, Loudi, Hunan 417000; \\ ${ }^{3}$ Department of Colorectal Surgery, The Affiliated Cancer Hospital of Xiangya School of Medicine, \\ Central South University, Changsha, Hunan 410013; ${ }^{4}$ Department of Oncology, \\ Loudi Central Hospital of Hunan Province, Loudi, Hunan 417000, P.R. China
}

Received April 21, 2015; Accepted July 3, 2015

DOI: $10.3892 /$ or.2015.4331

\begin{abstract}
R-34a is downregulated and a regulator of drug resistance in prostate cancer $(\mathrm{PCa})$. However, the mechanism of miR-34a in chemoresistance of $\mathrm{PCa}$ remains largely unknown. In the present study, we first confirmed the hypermethylation-induced downregulation of miR-34a in $\mathrm{PCa}$ tissues and cell lines, PC-3 and DU145. Additionally, transfection of miR-34a mimics and demethylation by 5-azacytidine both resulted in the upregulation of miR-34a expression, which further induced declined cell proliferation and the enhanced apoptosis in PCa cells. Upregulation of miR-34a enhanced the chemosensitivity of PC-3 and DU145 cells. Furthermore, overexpression of miR-34a reduced the expression of autophagy-related proteins, ATG4B, Beclin-1 and LC3B II/I in PCa cells and demethylation treatment showed similar effect. ATG4B was confirmed directly by miR-34a targeting in PCa. Finally, downregulated p-AMPK and upregulated p-mTOR were detected in miR-34a overexpressed PCa cells. Collectively, miR-34a enhances chemosensitivity by directly downregulating ATG4B-induced autophagy through AMPK/mTOR pathway in PCa.
\end{abstract}

\section{Introduction}

MicroRNAs are endogenous non-coding RNAs that can regulate gene expression through translational repression

Correspondence to: Professor Yang Xiao, Department of Orthopaedics, Loudi Central Hospital of Hunan Province, 51 Middle Changqing Street, Loudi, Hunan 417000, P.R. China

E-mail: xiao_yang168@sina.com.cn

Abbreviations: PCa, prostate cancer; miR-34a, microRNA-34a; Topo, Topotecan; Dox, doxorubicin; 5-Aza, 5-azacytidine

Key words: miR-34a, prostate cancer, methylation, autophagy, drug resistance and mRNA degradation (1). Accumulating evidence has shown their participation in the regulation of a wide range of biological processes, including tumor formation (2), since almost $50 \%$ of identified human miRNAs are found located at fragile sites on chromosomes that are known to be associated with cancer (3).

Human prostate cancer ( $\mathrm{PCa}$ ) is one of the most frequently diagnosed tumors, and the second significant cancer killer in males in America (4). Numerous studies have shown the involvement of miRNAs in prostate carcinogenesis in recent years $(5,6)$. There are more than 50 miRNAs found deregulated in PCa $(7,8)$, including miR-34a, one of the tumor-suppressor miRNAs (9). As a miRNA that induces cell cycle arrest and apoptosis (10), miR-34a displayed CpG promoter methylation in $\sim 80 \%$ of primary prostate carcinomas (11) and remarkable decrease in PCa cell lines (12). Additionally, miR-34 family is involved in drug resistance in PCa (12). However, the mechanism of miR-34a in chemoresistance of PCa still needs further research.

Autophagy is a highly conserved, organized catabolic process (13) and plays an important role in cancer $(14,15)$. High-level in tumor cells following anticancer treatment, therapeutic inhibitor targeting on the autophagic signaling pathway represents a novel avenue to reduce the occurrence of chemoresistance (16). Autophagy-related gene 4B (ATG4B), a controller on autophagosome maturation, is a particularly interesting target in this respect. Recent studies have described that many microRNAs (miRNAs) are involved in regulation of autophagic process by modulating autophagy-related genes (ATGs). miR-101 and miR-376b negatively regulates the expression of ATG4C and ATG4D $(17,18)$. miR-17 reduces ATG7 expression in glioblastoma cell lines (19). Notably, miR-34 represses autophagy by reducing the expression of ATG9 in mammalian cells (20). However, the mechanism of miR-34a on regulating autophagy and its role in drug resistance in PCa remains largely unknown.

In the present study, we detected the methylation condition of miR-34a in both PCa tissues and cell lines. Additionally, the changes of apoptosis and drug sensitivity in miR-34a 
methylated PCa cell lines were analyzed after transfection of miR-34a or demethylation treatment using 5-azacytidine (5-Aza). Furthermore, the target relation between miR-34a and ATG4B in PCa was investigated. Finally, AMPK/mTOR pathway was examined for its involvement in miR-34a-induced regulation process. Our research may supply a novel choice for the future treatment on PCa chemoresistance.

\section{Materials and methods}

Isolation of PCa and adjacent tissues. Human PCa tissue and the corresponding adjacent normal tissue were isolated during the operation, with the written consent of the patients.

Cell culture. Human PCa cell lines, including PC-3, DU145 and RWPE-1 were purchased from Auragene (Changsha, China). Cells were cultured as monolayer in RPMI-1640 medium (HyClone, Logan, UT, USA) supplemented with $10 \%$ fetal calf serum (Gibco, Gaithersburg, MD, USA) and $2 \mathrm{mM}$ glutamax.

For demethylation treatment, all PCa cells were treated with $10 \mu \mathrm{mol} / 1$ 5-Azacytidine (Sigma-Aldrich, St. Louis, MO, USA) for $48 \mathrm{~h}$. Cells were then harvested for the following investigations.

Transfection. PC-3 and Du145 cells were cultured as previously described before transfection. Mimics NC (100 pmol) or pre-miR-34a (Auragene) was diluted in $250 \mu \mathrm{l}$ serum-free RPMI-1640 medium, which was then mixed with $10 \mu \mathrm{l}$ of Lipofectamine 2000 (diluted in $250 \mu \mathrm{l}$ serum-free medium). After incubation at $37^{\circ} \mathrm{C}$ for $4 \mathrm{~h}$, the medium was replaced by complete medium for another $48 \mathrm{~h}$ culture. Cells were then collected for use.

MTT assay. For proliferation analysis of PCa cells, 5,000 cells were plated in three 96-well plates. After every $24 \mathrm{~h}$ incubation at $37^{\circ} \mathrm{C}$ and $5 \% \mathrm{CO}_{2}$, one plate was taken out and the cells were treated with $20 \mu \mathrm{l}$ MTT solution $(5 \mathrm{mg} / \mathrm{ml})$ for $4 \mathrm{~h}$. Subsequently, MTT solution was replaced by $150 \mu \mathrm{l}$ of dimethylsulfoxide (DMSO) to dissolve the tetrazolium crystals. The OD values were read at a test wavelength of $570 \mathrm{~nm}$ with a microplate reader within $10 \mathrm{~min}$ (Thermo Labsystems, Cheshire, UK).

For the evaluation of the PCa cell sensitivity to chemotherapy, after seeded on 96-well plates, the medium was replaced by chemotherapeutic drug (Dox, $4.0 \mu \mathrm{mol} / 1$; Topo, $5 \mathrm{mg} / \mathrm{l})$. After $72 \mathrm{~h}, 20 \mu \mathrm{l} \mathrm{MTT}$ solution $(5 \mathrm{mg} / \mathrm{ml})$ was added to each well. MTT solution was replaced by $150 \mu 1$ of DMSO to dissolve the tetrazolium crystals after $4 \mathrm{~h}$ incubation at room temperature. The absorption was read at the wavelength of $570 \mathrm{~nm}$ with a microplate reader within $10 \mathrm{~min}$.

Apoptotic assay. Annexin $\mathrm{V}$ apoptosis detection kit (Life Technologies, Grand Island, NY, USA) was used for apoptosis detection. After cultured in $0.0625 \mu \mathrm{M}$ Dox or $0.0195 \mathrm{mg} / \mathrm{l}$ Topo for $48 \mathrm{~h}$, cells were trypsinized, collected and washed twice with cold phosphate-buffered saline (PBS). Binding buffer $(500 \mu \mathrm{l})$ was used to resuspend cells. Annexin V-FITC (5 $\mu \mathrm{l})$ and $5 \mu \mathrm{l}$ propidium iodide were added to the solution and mixed well. Following $15 \mathrm{~min}$ incubation at room temperature in the dark, cells were analyzed using flow cytometric analysis (BD Biosciences, San Jose, CA, USA).

Quantitative-polymerase chain reaction ( $q$-PCR) analysis of $m R N A$ expression. Total RNA containing miRNA was extracted from PCa and adjacent tissues, and PC-3 and DU145 cells with the use of TRIzol reagent (Life Technologies, Shanghai, China) according to the manufacturer's instructions, and cDNA was synthesized using TaqMan MicroRNA Reverse Transcription kit (Applied Biosystems, Foster City, CA, USA). q-PCR was performed with the use of fluorescence quantitative PCR instrument (ABI 7500 thermocycler; Life Technologies) and SYBR-Green Universal PCR Master Mix (Bio-Rad, Hercules, CA, USA). The expression level of miR-34a was normalized to RNU6B. Oligonucleotide sequences of the primer sets used were as follows: miR-34a, HmiRQP0440; U6, HmiRQP9001; human ATG4B (sense, 5'-ATGACTTCAATGATTGGTGCC-3' and antisense, 5'-AG AAGAATCTGGACTTGGCAG-3'); human $\beta$-actin (sense, 5'-AGGGGCCGGACTCGTCATACT-3' and antisense, 5'-GG CGGCACCACCATGTACCCT-3'). PCR was performed in a total volume of $20 \mu \mathrm{l}$, which included $10 \mu \mathrm{l}$ of $2 \mathrm{X}$ SYBR-Green qPCR mix, $1 \mu \mathrm{l}$ of each forward and reverse primer $(10 \mu \mathrm{mol} / \mathrm{l})$, $1 \mu \mathrm{l}$ each cDNA sample and $7 \mu 1 \mathrm{H}_{2} \mathrm{O}$. Amplifications were carried out in triplicate in 96-well microtiter plates. Thermal cycling conditions were as follows: $95^{\circ} \mathrm{C}$ for $3 \mathrm{~min}$, followed by 35 cycles of $95^{\circ} \mathrm{C}$ for $10 \mathrm{sec}$, and $58^{\circ} \mathrm{C}$ for $30 \mathrm{sec}$, and finally by $95^{\circ} \mathrm{C}$ for $12 \mathrm{sec}, 58^{\circ} \mathrm{C}$ for $50 \mathrm{sec}$.

Western blotting. Whole-cell lysates were harvested and washed with PBS, and then lysed in a buffer containing $150 \mathrm{mM} \mathrm{NaCl}, 1 \mathrm{mM}$ PMSF, $\mathrm{NaVO}_{4}$, aprotinin and leupeptin as protease inhibitors, in $50 \mathrm{mM}$ Tris- $\mathrm{HCl} \mathrm{pH} 8.0,0.2 \%$ SDS, $1 \%$ NP-40. Protein/sample $(30 \mu \mathrm{g})$ was resolved on a SDS-PAGE gel with subsequent transfer blotting. Membranes were incubated at $4^{\circ} \mathrm{C}$ with primary antibody overnight [m-TOR, YT2915; p-m-TOR, YP0176; ATG4B, YT0394; (all from Immunoway) Beclin-1, 2026-1; Epitomics; LC3B, ab51520; Abcam; Bax, YT0456; Bcl2, YT0469 (both from Immunoway), caspase 3, ab2302; caspase 9, ab2324 (both from Abcam)]. After washing, membranes were incubated with the corresponding secondary antibody preparation for $1 \mathrm{~h}$ at room temperature, followed by chemiluminescence for visualization. For control group, the membrane was stripped and reprobed using an actin antibody after the probing of each membrane with the primary antibody.

Dual-luciferase reporter gene assay. For the luciferase reporter experiments, a 3'-untranslated region (3'-UTR) segment of ATG4B gene (accession no. NM_013325.4) was amplified by PCR from human genomic DNA using primers that included an XhoI and a NotI tail on the 5' and 3 ' strands, respectively. $\mathrm{PCR}$ products were recombined with psi-CHECK2. The PC-3 and DU145 cells were then transfected with the firefly luciferase ATG4B-3'UTR-psi-CHECK2, combined with miR-34a mimics. Twenty-four hours after transfection, cells were lysed with a $1 \mathrm{X}$ passive lysis buffer and the activity of both Renilla and firefly luciferase was assayed using the DualLuciferase Reporter Assay system (Promega) according to the manufacturer's instructions. 

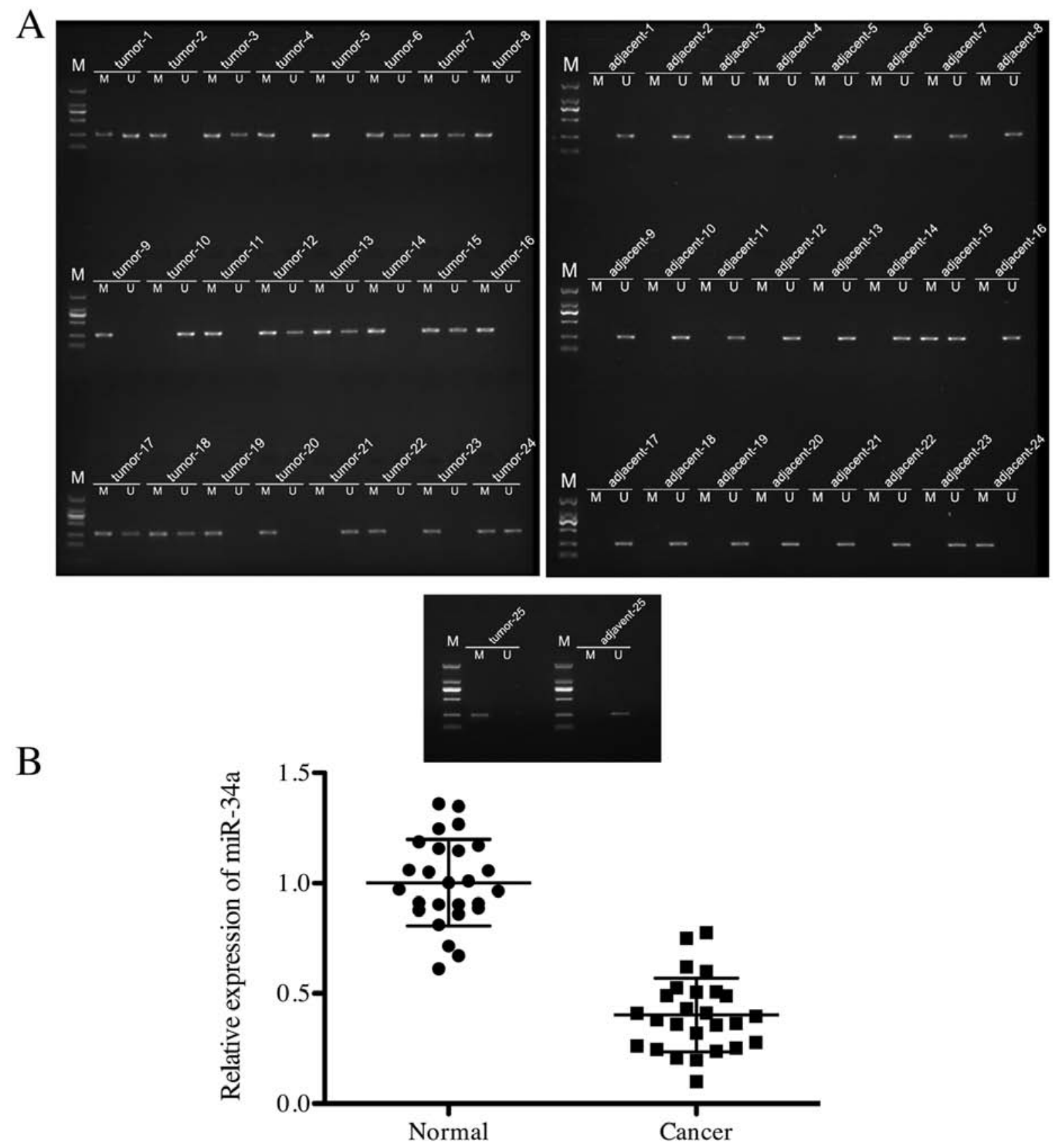

Figure 1. Expression of miR-34a is downregulated in prostate cancer tissue. (A) DNA was isolated from both 25 PCa and 25 adjacent tissue samples, subjected to bisulfite conversion and analyzed by MSP with primers specific for methylated (M) and unmethylated (U) miR-34a promoter DNA, respectively. (B) miR-34a expression was determined in 25 PCa tissues and 25 normal adjacent tissues by q-PCR. Data are normalized to the RNA control U6 snRNA. $\mathrm{PCa}$, prostate cancer.

DNA methylation analysis using MSP. Genomic DNA from PCa tissues and cell lines was isolated with Auragene Genomic DNA kit (Auragene Biotech, Changsha, China). MSP was performed in a total volume of $20 \mu 1$ using 1.5 units Platinum Taq Polymerase (Invitrogen) per reaction. Oligonucleotide sequences used for the MSP were: miR-34a-MSP-F, TGT TAGTTTTTTCGGGGAGTTTTCGG and miR-34a-MSP-R, ACGCCAACTCCTCCCCCGTCCCGAAC; miR-34aUMSP-F, TAGTTTTTTTGGGGAGTTTTTGGTTT and miR-34a-UMSP-R, TAACACCAACTCCTCCCCCATC CCAA. PCR was performed in a total volume of $15 \mu \mathrm{l}$, which included $1.5 \mu \mathrm{l}$ of 10X LAmp buffer, $1.2 \mu \mathrm{l}$ of dNTP mix, $0.5 \mu \mathrm{l}$ of forward and reverse primer $(10 \mu \mathrm{M}), 0.3 \mu \mathrm{l}$ of LAmp
Taq, $3 \mu 1$ of $5 \mathrm{X}$ C Solution I, $1 \mu 1$ of template and $7 \mu 1$ of $\mathrm{ddH}_{2} \mathrm{O}$. Amplifications were carried out in 96-well microtiter plates. Thermal cycling conditions were: $94^{\circ} \mathrm{C}$ for $4 \mathrm{~min}$, followed by 35 cycles of $94^{\circ} \mathrm{C}$ for $30 \mathrm{sec}, 58^{\circ} \mathrm{C}$ for $30 \mathrm{sec}$ and $72^{\circ} \mathrm{C}$ for $30 \mathrm{sec}$, and finally followed by $72^{\circ} \mathrm{C}$ for $5 \mathrm{~min}$. Amplified fragments were separated by electrophoresis on $8 \%$ polyacrylamide gels and visualized by staining with ethidium bromide.

Statistical analysis. Data are expressed as mean \pm standard deviation (SD). Comparisons between groups were performed by one-way analysis of variance (ANOVA) using SPSS 17.0 (SPSS, Inc., USA) and Prism 5.0 (GraphPad Software, USA). 


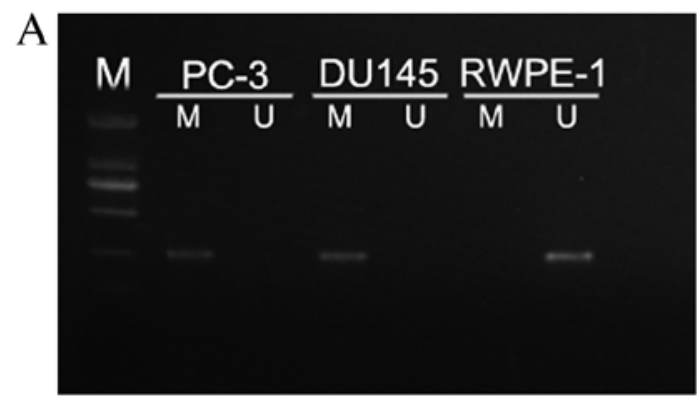

B

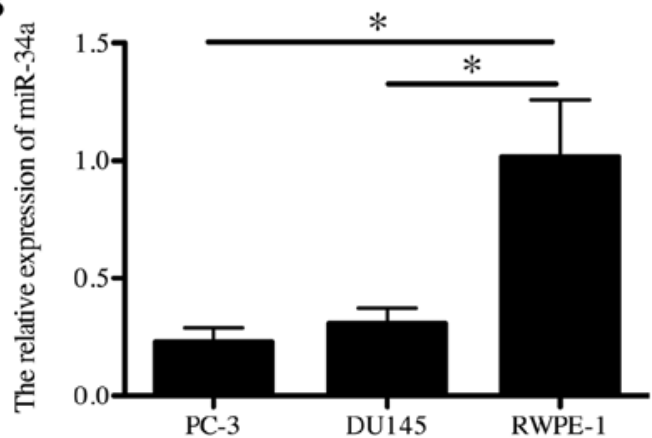

$\mathrm{C}$

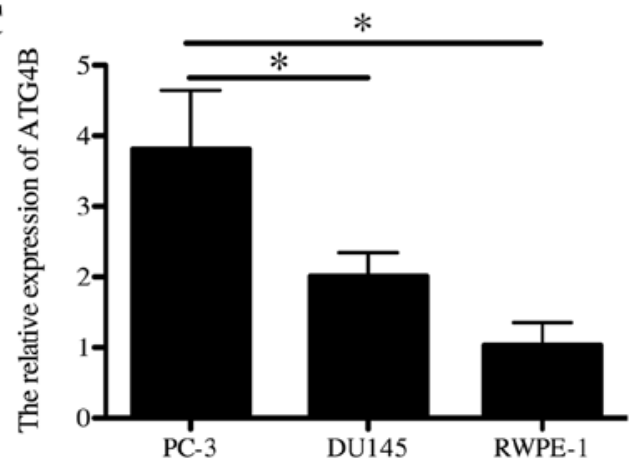

Figure 2. miR-34a is hypermethylated while expression of ATG4B is at high level in PC-3 and DU145 cells, yet not in RWPE-1 cells. (A) DNA was isolated from PC-3, DU145 and RWPE-1 cells, subjected to bisulfite conversion and analyzed by MSP with primers specific for methylated (M) and unmethylated (U) miR-34a promoter DNA, respectively. (B) Quantification of relative expression of miR-34a in three PCa cell lines by q-PCR. Bars represent mean values \pm SD. ${ }^{*} \mathrm{P}<0.05$. $\mathrm{N}=3$ for each group. (C) Quantification of relative expression of ATG4B in three PCa cell lines by q-PCR. Bars represent mean values \pm SD. "P $<0.05$. $\mathrm{N}=3$ for each group. $\mathrm{PCa}$, prostate cancer.

$\mathrm{P}<0.05$ was considered to indicate a statistically significant result.

\section{Results}

miR-34a is epigenetically downregulated by DNA methylation in PCa tissue. To determine the methylation condition of miR-34a in PCa cells, 25 samples of PCa and adjacent tissues were collected and measured in MSP, respectively. As shown in Fig. 1A, 23 in 25 (92\%) PCa tissue samples showed methylated miR-34a, while only 3 in 25 (12\%) adjacent tissue samples displayed positive methylation on miR-34a. Furthermore, expression of miR-34a in PCa and cancer adjacent tissues was quantified by q-PCR. The relative expression of miR-34a in adjacent tissue was significantly higher than that in $\mathrm{PCa}$ tissue (Fig. 1B). This indicated that miR-34a was hypermethylated in PCa tissue.

Methylation of miR-34a and expression of ATG4B in PCa cell lines. To analyze the methylation condition of miR-34a in $\mathrm{PCa}$ cell lines in vitro, PC-3, DU145 and RWPE-1 were detected in MSP. miR-34a showed methylated in PC-3 and DU145 while RWPE-1 was unmethylated (Fig. 2A). Additionally, the relative expression of miR-34a and mRNA of ATG4B was respectively detected in all cell lines in q-PCR. Consistently, PC-3 and DU145 showed significantly lower expression of miR-34a than RWPE-1 (p<0.05; Fig. 2B), while the mRNA level of ATG4B in RWPE-1 was lower than the other two cell lines ( $p<0.05$; Fig. 2C). The above demonstrated that PC-3 and DU145 showed miR-34a methylation and kept low expression of miR-34a, while ATG4B was highly expressed.
Upregulation of miR-34a promotes cell apoptosis in PC-3 and DU145 cells. We performed gain-of-function studies using miR-34a mimics, and miRNA transfection efficiency was determined by q-PCR. After PC-3 and DU145 cells were transfected with miR-34a mimics, the expression of miR-34a was significantly upregulated ( $\mathrm{p}<0.01$, Fig. 3A). 5-Aza treatment also increased the level of miR-34a (Fig. 3A). This indicated that the original low level of miR-34a in PCa cells was related to methylation. Additionally, the effects of upregulation of miR-34a either by transfection or by demethylation treatment on cell proliferation in PC-3 and DU145 cells were examined by MTT assay. Transfection of miR-34a mimics resulted in a significant decrease in cell growth of PCa cell lines (PC-3, $\mathrm{p}<0.05$; DU145, $\mathrm{p}<0.01$ ), and demethylation treatment also led to a statistical decrease $(\mathrm{p}<0.05)$ in proliferation of DU145 cells (Fig. 3B). We further investigated the effect of miR-34a on cell apoptosis using western blotting (Fig. 3C). Apoptosis related proteins, caspase $3(\mathrm{p}<0.01)$, caspase $9(\mathrm{p}<0.01)$ and Bax $(\mathrm{p}<0.01)$, were all significantly upregulated after transfection in both PC-3 and DU145 cells, and anti-apoptosis protein Bcl-2 was statistically downregulated $(\mathrm{p}<0.01)$ (Fig. 3D). These data indicated that miR-34a has a vital role in reducing the growth of PCa cells.

Upregulation of miR-34a enhances the sensitivity of $P C-3$ and DU145 cells to Dox and Topo. The effects of upregulation of miR-34a on cell chemosensitivity in PC-3 and DU145 cells were examined by MTT assay. Transfection with miR-34a mimics resulted in a significant decrease on $\mathrm{IC}_{50}$ value when PCa cell lines were treated with Dox $(\mathrm{p}<0.05$, Fig. 4A) and Topo (p<0.05, Fig. 4B), respectively. 5-Aza treatment led to 


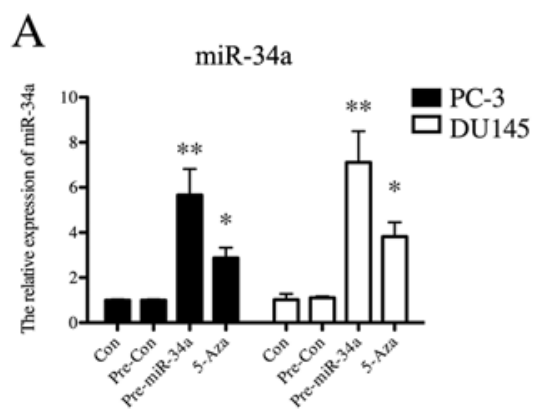

B
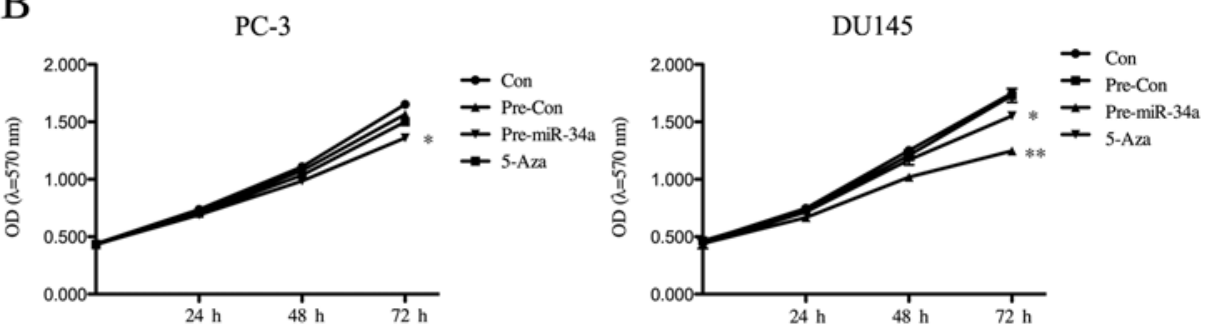

$\mathrm{D}$
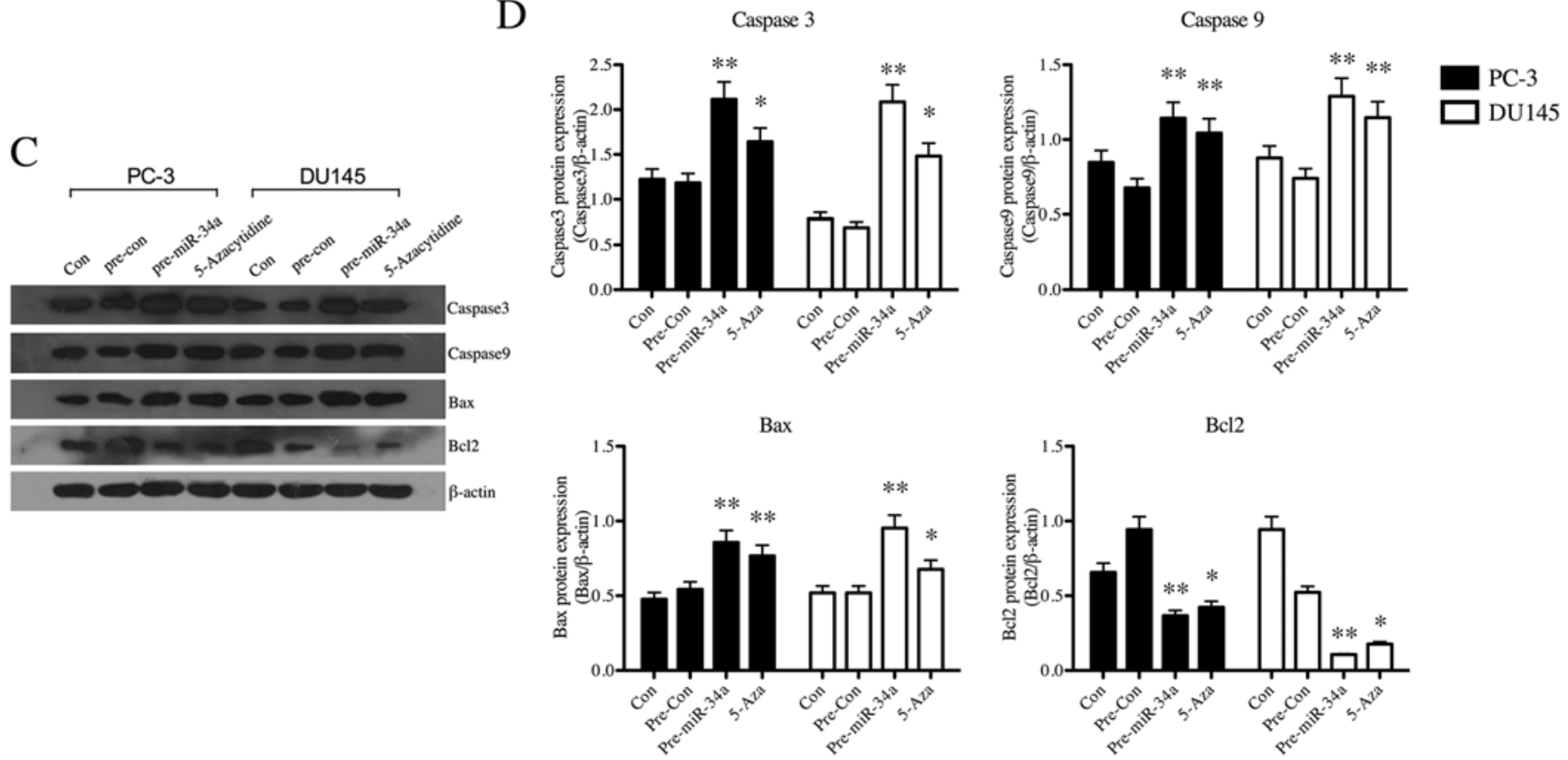

Figure 3. Upregulation of miR-34a promotes apoptosis in PC-3 and DU145 PCa cell lines. (A) PC-3 and DU145 cells were transfected with miR-34a mimics (Pre-miR-34a) or blank mimics (Pre-Con), and miR-34a expression was confirmed by q-PCR in PC-3 and DU145 cells $48 \mathrm{~h}$ after transfection. 5-Aza treatments were used as demethylation agents on miR-34a. Bars represent mean values $\pm \mathrm{SD}$. ${ }^{* *} \mathrm{P}<0.01 ;{ }^{*} \mathrm{P}<0.05$. $\mathrm{N}=3$ for each group. (B) Cellular proliferation was measured in the control and miR-34a mimic-transfected PC-3 (left) and DU145 (right) cells using an MTT assay at 3-time points. 5-Aza treatments were used as demethylation agents on miR-34a. Bars represent mean values $\pm \mathrm{SD} .{ }^{* *} \mathrm{P}<0.01 ;{ }^{*} \mathrm{P}<0.05$. $\mathrm{N}=3$ for each group. (C) Apoptosis-related proteins including caspase 3 and 9, Bax and Bcl2 were measured in the control and miR-34a mimic-transfected PC-3 and DU145 cells by western blotting. 5-Aza treatments were used as demethylation agents on miR-34a. (D) Quantification of protein expression of caspase 3 and 9, Bax and Bcl2. Bars represent mean values \pm SD. ${ }^{* *} \mathrm{P}<0.01 ;{ }^{*} \mathrm{P}<0.05 . \mathrm{N}=3$ for each group. $\mathrm{PCa}$, prostate cancer.

a statistical decrease $(\mathrm{p}<0.01)$ on $\mathrm{IC}_{50}$ value of both cell lines when treated with Dox and Topo (Fig. 4A and B). This indicated that upregulation of miR-34a induced by overexpression or demethylation enhanced the drug sensitivity in PCa cells. We further investigated the effect of miR-34a upregulation on cell apoptosis in Dox and Topo using flow cytometry (Fig. 4C). Based on the data shown in Fig. 4D, Dox $(\mathrm{p}<0.05)$ and Topo $(\mathrm{p}<0.05)$ treatment led to an increased apoptosis percentage in PCa cells compared with control. Upregulation of miR-34a in both cell lines induced by mimics transfection $(p<0.05)$ or 5 -Aza treatment $(\mathrm{p}<0.05)$ significantly increased the apoptosis percentage of cells that were cultured in Dox and Topo, compared with non-treated cells in Dox or Topo, respectively. miR-34a-upregulated PC-3 and DU145 cells showed higher apoptosis percentage in both Dox $(\mathrm{p}<0.01)$ and Topo $(\mathrm{p}<0.01)$ than the control group. Collectively, these data demonstrated that overexpression of miR-34a or demethylation on miR-34a in PC-3 and DU145 cells improved cell chemosensitivity to Dox and Topo.
Upregulation of miR-34a impairs autophagy by directly downregulating ATG4B in PC-3 and DU145 cells. For the analysis of the effects of miR-34a on regulating autophagy-related proteins, the expression of AGT4B was first examined in PCa cells. mRNA expression of ATG4B in PC-3 $(p<0.01)$ and DU145 $(\mathrm{p}<0.01)$ was statistically reduced after transfection of miR-34a mimics, which was similar to the effect of 5-Aza on PCa cells (PC-3, p<0.05; DU145, p<0.05) (Fig. 5A). The protein expression of ATG4B and autophagy-related proteins, Beclin-1 and LC3B II/I, were then detected in both cell lines (Fig. 5B). Both the PC-3 and DU145 cells after transfection displayed significantly downregulated level of ATG4B protein $(\mathrm{p}<0.01)$, Beclin-1 $(\mathrm{p}<0.01)$ and LC3B II/I $(\mathrm{p}<0.01)$ (Fig. 5C). 5-Aza treatment similarly led to the decrease of ATG4B $(\mathrm{p}<0.05)$, Beclin-1 $(\mathrm{p}<0.05)$ and LC3B II/I ( $<<0.05)$ (Fig. 5C). Furthermore, dual-luciferase reporter gene assay was operated to examine whether ATG4B is indeed functionally targeted by miR-34a. Fig. 5D shows that miR-34a inhibited the luciferase activity from the construct with the ATG4B-3'-UTR segment 
A

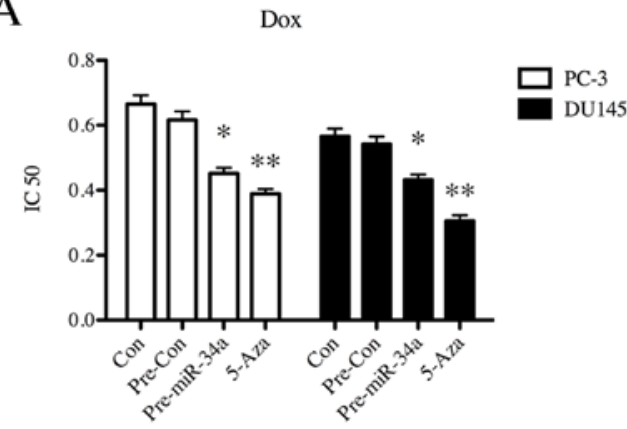

C
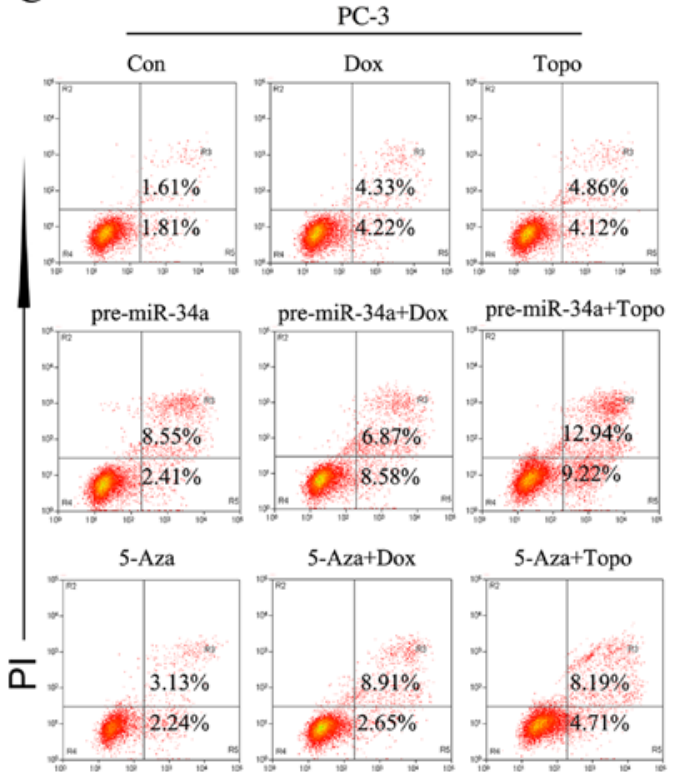

5-Aza+Dox

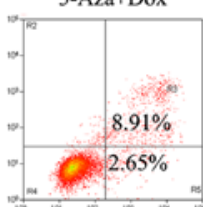

5-Aza+Topo

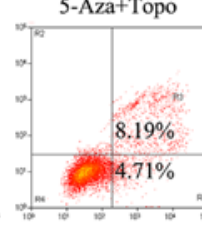

FITC
B
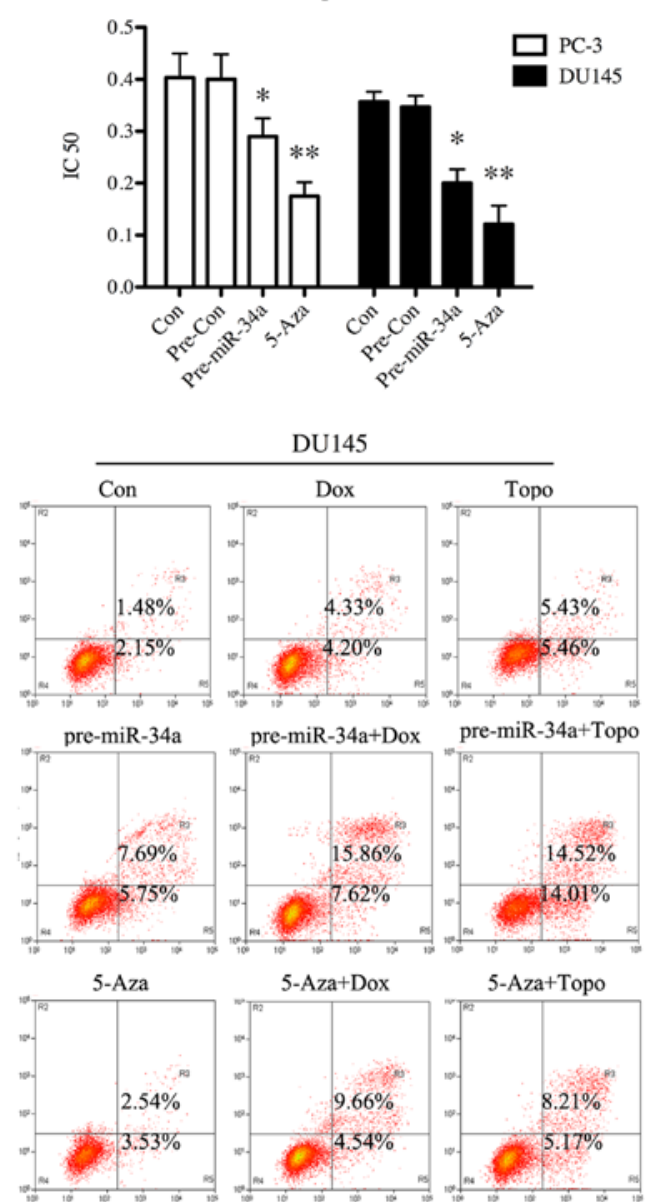

5-Aza+Dox

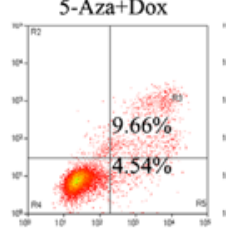

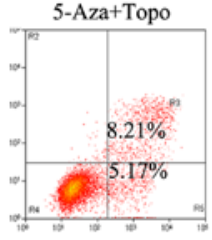

D

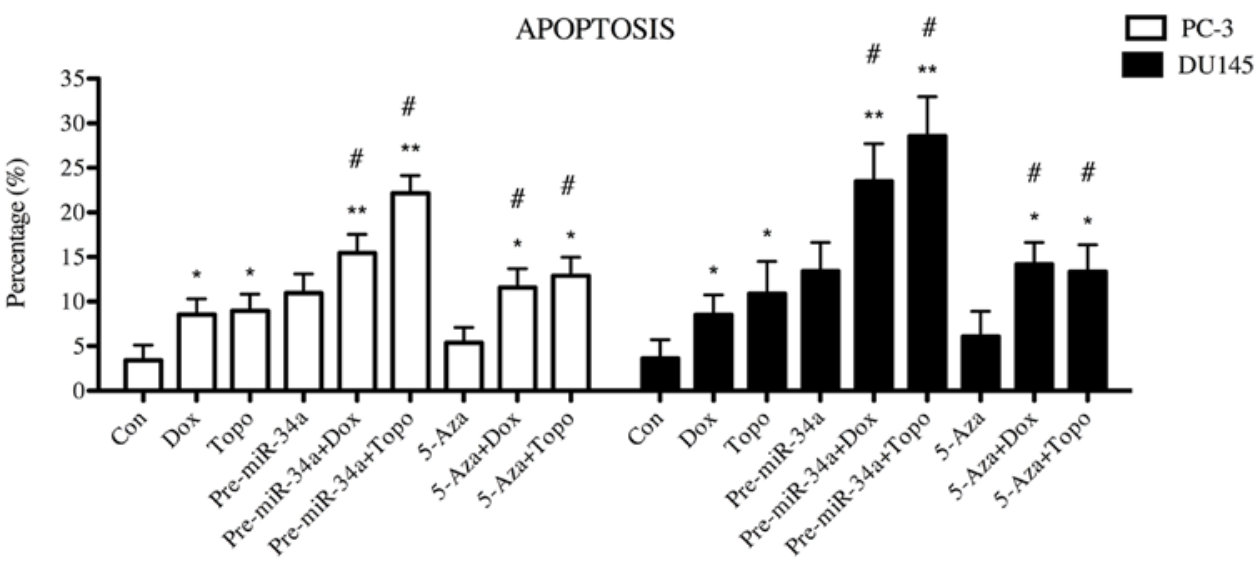

Figure 4. miR-34a sensitizes PC-3 and DU145 cells to chemotherapy-induced apoptosis. (A) $\mathrm{IC}_{50}$ value of the control and miR-34a mimic-transfected PC-3 and DU145 cells in Dox medium was measured using MTT assay at 48 h. 5-Aza treatments were used as demethylation agents on miR-34a. Bars represent mean values $\pm \mathrm{SD}$. ${ }^{* *} \mathrm{P}<0.01 ;{ }^{*} \mathrm{P}<0.05$. $\mathrm{N}=3$ for each group. (B) $\mathrm{IC}_{50}$ value of the control and miR-34a mimic-transfected PC-3 and DU145 cells in Topo medium was measured using MTT assay at 48 h. 5-Aza treatments were used as demethylation agents on miR-34a. Bars represent mean values $\pm \mathrm{SD}$. ${ }^{* * *} \mathrm{P}<0.01$; ${ }^{\mathrm{P}} \mathrm{P}<0.05$. $\mathrm{N}=3$ for each group. (C) Apoptosis of PC-3 (left) and DU145 (right) cells with or without miR-34a mimic transfection in Dox and Topo medium was detected by flow cytometry. 5-Aza treatments were used as demethylation agents on miR-34a. The right hand of the quadrant indicates apoptotic cell population. (D) Statistical analysis of apoptosis condition of PCa cell lines in different treatment groups. Bars represent mean values $\pm \mathrm{SD} .{ }^{*} \mathrm{P}<0.05$, compared with Dox or Topo group. ${ }^{* *} \mathrm{P}<0.01 ;{ }^{*} \mathrm{P}<0.05$, compared with Con group. $\mathrm{N}=3$ for each group. $\mathrm{PCa}$, prostate cancer.

both in PC-3 ( $\mathrm{p}<0.01)$ and DU145 cells $(\mathrm{p}<0.01)$. There was no change in the luciferase reporter activity when the cells were cotransfected with the miR-34a-inhibitor or negative controls. This demonstrated that ATG4B was a direct target of miR-34a in PC-3 and DU145 cells.
miR-34a regulates $A T G 4 B$-induced autophagy through the $A M P K / m T O R$ pathway. In order to investigate the pathway by which miR-34a regulates autophagy in PCa cells, we performed western blotting for the analysis of protein expression in the AMPK/mTOR pathway (Fig. 6A). As shown in Fig.6B, the level 
A

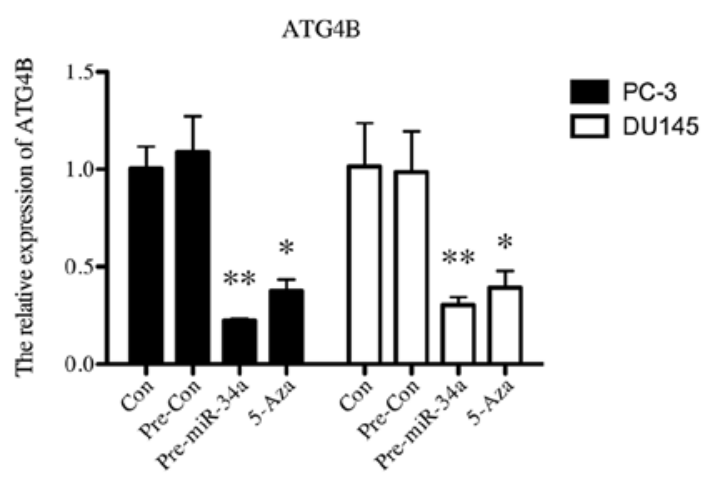

B

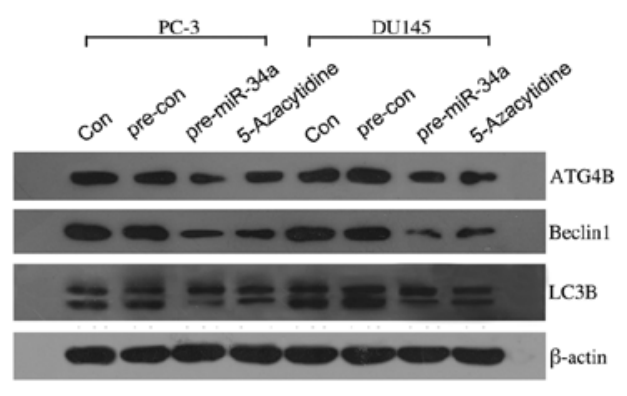

$\mathrm{C}$
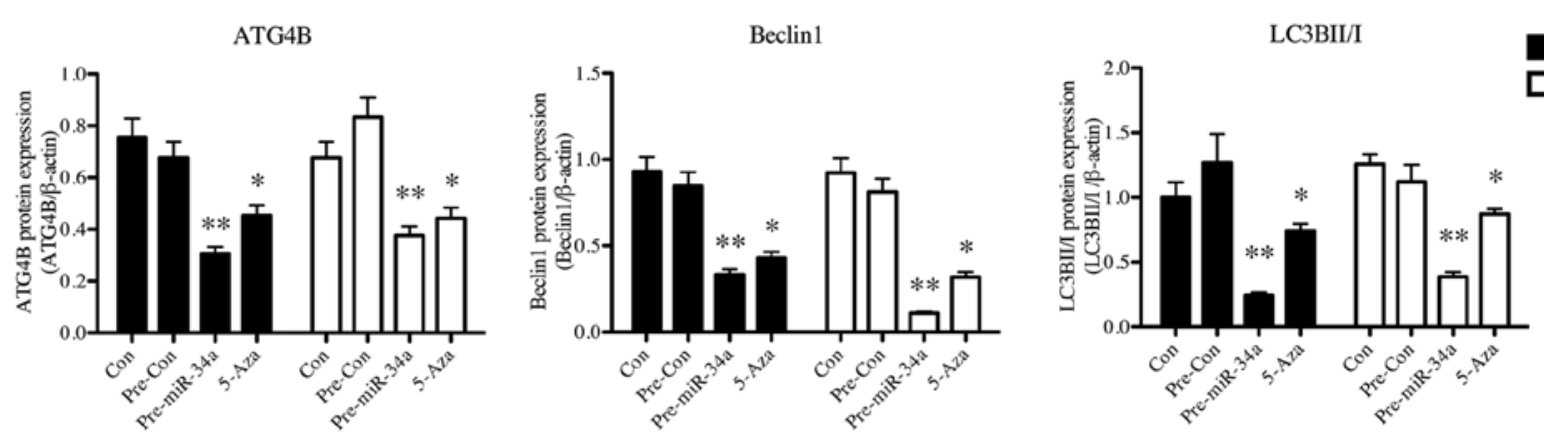

$\mathrm{D}$
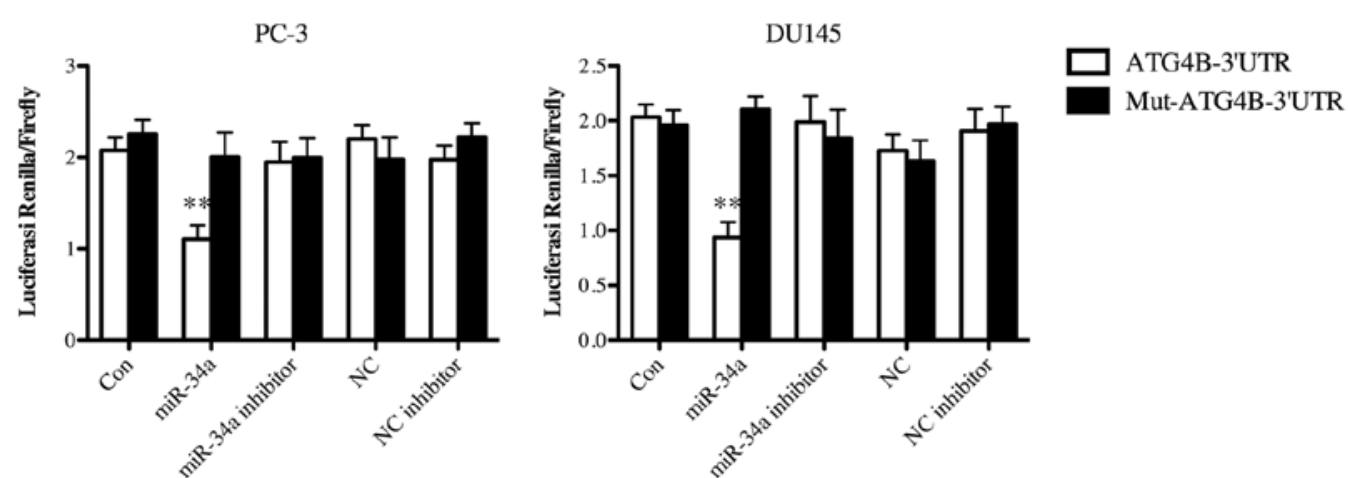

Figure 5. Reconstitution of miR-34a impairs autophagy by directly downregulating ATG4B in PC-3 and DU145 cells. (A) Effects of overexpression of miR-34a on ATG4B expression in PC-3 and DU145 cells. The mRNA expression level of ATG4B was measured by q-PCR in PC-3 and DU145 cells 48 h after transfection, respectively. Bars represent mean values $\pm \mathrm{SD}$. ${ }^{* *} \mathrm{P}<0.01 ;{ }^{*} \mathrm{P}<0.05$. $\mathrm{N}=3$ for each group. (B) For protein expression analysis, $\mathrm{ATG} 4 \mathrm{~B}$, Beclin-1 and LC3B II/I in PC-3 and DU145 were measured after transfection by western blotting, respectively. (C) Quantification of protein expression of ATG4B, Beclin-1 and LC3B II/I. Bars represent mean values $\pm \mathrm{SD}$. ${ }^{* *} \mathrm{P}<0.01 ;{ }^{*} \mathrm{P}<0.05$. N=3 for each group. (D) Dual-luciferase reporter gene assay for targeting ATG4B. PC-3 (left) and DU145 (right) cells were transfected with ATG4B-3'-UTR, combined with miR-34a or miR-34a-inhibitor or the negative controls. Twenty-four hours after transfection, cells were lysed and the activity of both Renilla and firefly luciferase was assayed by the dual-luciferase reporter assay system. Bars represent mean values $\pm \mathrm{SD}$. ${ }^{* *} \mathrm{P}<0.01$. $\mathrm{N}=3$ for each group.

of phosphorylated AMPK was significantly downregulated in chemotherapy-treated group. Overexpression of miR-34a also led to a decrease on expression of phosphorylated AMPK, while silence of miR-34a resulted in a significant upregulation. Additionally, $\mathrm{p}-\mathrm{mTOR}$ was significantly reduced when miR-34a was overexpressed in PC-3 or DU145 cells, and anti-miR-34a statistically upregulated the expression of p-mTOR (Fig. 6C). Besides, the treatments with Dox or Topo on cells resulted in an increase on p-mTOR expression (Fig. 6C). Furthermore, the expression of autophagy-related proteins were downregulated after miR-34a overexpression, including ATG4B (Fig. 6D), Beclin-1 (Fig. 6E) and LC3B II/I (Fig. 6F). The anti-miR-34a transfection reversed the low expression level of these proteins, with a significant increase compared with control group (Fig. 6D-F). These data collectively indicated that
miR-34a induced the downregulation of autophagy-related proteins, ATG4B, Beclin-1 and LC3B II/I, through the AMPK/mTOR pathway.

\section{Discussion}

Accumulating evidences have shown the decrease of miR-34a in prostate cancer $(\mathrm{PCa})$ and its relation with drug resistance (12). Autophagy also plays an important role in chemoresistance of cancer (14-16). However, whether the chemoresistance induced by miR-34a is related to ATG4B in PCa, including their mechanism on chemoresistance, still further research is needed. In the present study, we found that upregulation of miR-34a induced by mimic transfection and demethylation treatment using 5-azacytidine (5-Aza) resulted 

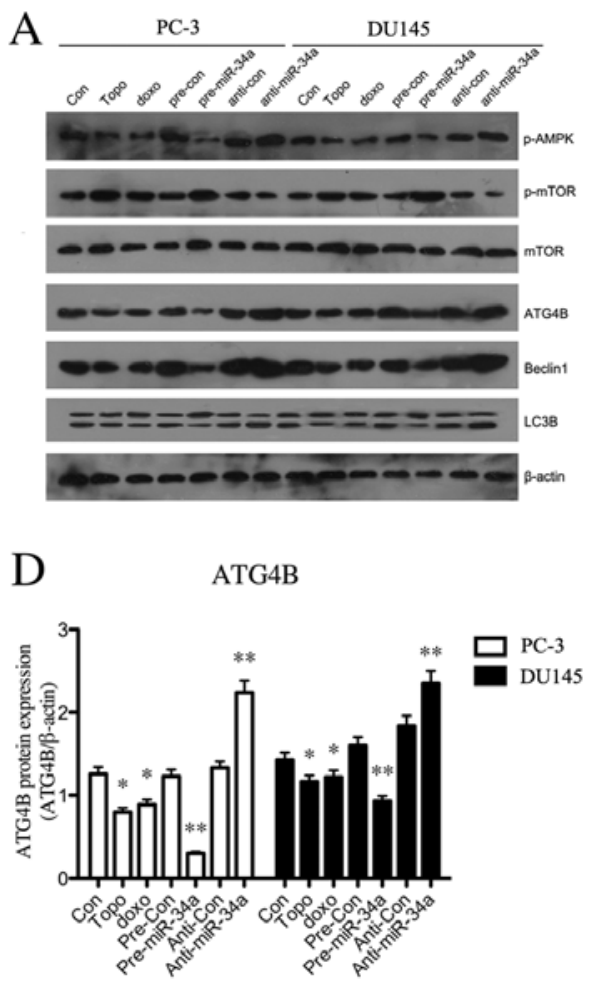

B

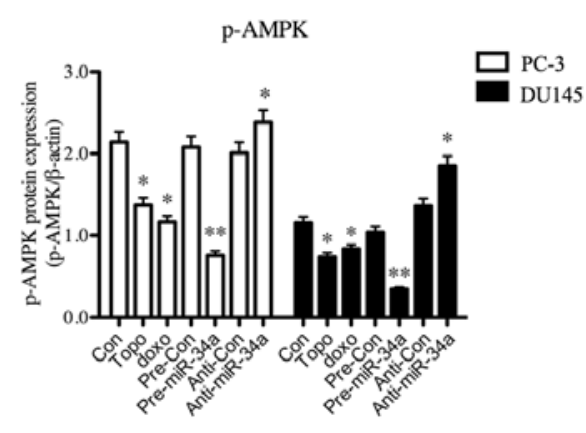

$\mathrm{E}$

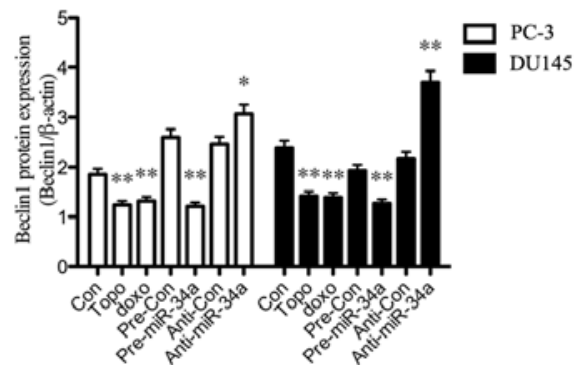

$\mathrm{C}$

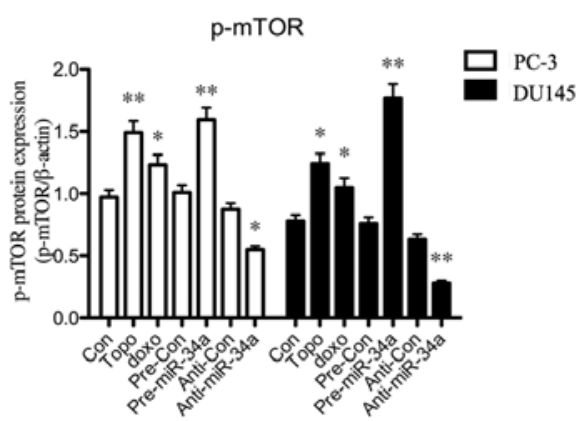

$\mathrm{F}$

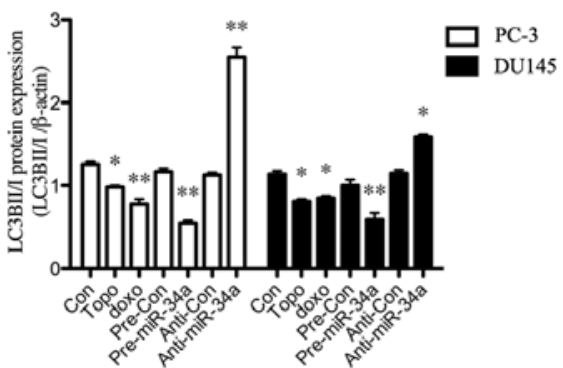

Figure 6. Effects of overexpression of miR-34a on mTOR phosphorylation and the expression of ATG4B, Beclin-1 and LC3B II/I in PC-3 and DU145 cells. (A) Forty-eight hours after transfection with either miR-34a mimics (Pre-miR-34a) or anti-miR-34a mimics (Anti-miR-34a) or blank mimics (Pre-Con and Anti-Con) as control in PC-3 and DU145 cells, cells were subjected to western blot analysis. (B-F) Quantification of protein expression of (B) p-AMPK, (C) p-mTOR, (D) ATG4B, (E) Beclin-1 and (F) LC3B II/I. Bars represent mean values \pm SD. ${ }^{* *} \mathrm{P}<0.01$; ${ }^{*} \mathrm{P}<0.05$; compared with Con group. N=3 for each group.

in the enhanced apoptosis and chemosensitivity in $\mathrm{PCa}$ cells. Overexpression of miR-34a reduced the expression of autophagy-related proteins, ATG4B, Beclin-1 and LC3B II/I in $\mathrm{PCa}$ cells by downregulating $\mathrm{p}-\mathrm{AMPK}$ and upregulating p-mTOR in PCa cells.

We detected the hypermethylation condition of miR-34a in PCa tissues and cell lines such as PC-3 and DU145. Previously, several lines of evidence demonstrated miR-34a promoter methylation in many types of cancers (11). Moreover, Lodygin et al demonstrated that the loss of miR-34a expression associated with the methylation of promoter $\mathrm{CpG}$ island was found in the majority $(79.1 \%)$ of primary prostate carcinoma samples (11). Additionally, miR-34a expression was markedly reduced in PCa cell lines (12). There data are in accordance with our findings. Notably, miR-34a is even linked to $\mathrm{PCa}$ metastasis, suggesting that it could be a potential biomarker for PCa (21).

In addition, we found miR-34a effective on PCa cell apoptosis. Previously, Bommer et al showed that Bcl-2 is targeted by miR-34a (22). Welch et al also found the re-expression of miR-34a induced restoration of apoptosis through the activation of caspases 3 and 7 in neuroblastoma (23). Besides, miR-34a synthetic mimics were proved to trigger growth inhibition and apoptosis in multiple myeloma cells by downregulating canonic targets BCL-2, CDK6 and NOTCH1 in vitro and in vivo (24). All these data were in accordance with our findings. Additionally, Nalls et al revealed that re-expression of miR-34a in pancreatic CSCs inhibited cell growth, cell cycle progression, self-renewal, epithelial to mesenchymal transition and invasion (25). Forced expression of miR-34a was able to significantly suppress tumor growth in an orthotopic mouse model of breast cancer (26). Using chemically synthesized miR-34a and a lipid-based delivery vehicle efficiently inhibited tumor growth without liver or kidney toxicity and immune response in a mouse lung tumor model (27). Therefore, upregulation of miR-34a could be an attractive new therapeutic strategy to improve treatment outcome of cancer.

Furthermore, accumulating evidence demonstrated that miR-34 family is involved in drug resistance in PCa. For example, re-expression of miR-34a attenuated chemoresistance to anticancer drug camptothecin via induction of apoptosis in PCa (12), also in agreement with our findings. We found that upregulation of miR-34a by transfection of mimics resulted in enhanced chemosensitivity in PCa cells, which proved the role of miR-34a in chemoresistance. Besides, we also found 5-Aza treatment resulted in similar effect with transfection of miR-34a mimics. This indicated the epigenetic regulation on miR-34a in PCa was significantly responsible for the chemoresistance in PCa. Notably, recent studies have described that miRNAs are involved in regulation of autophagic process by modulating autophagy-related genes (ATGs). miR-101 and miR-376b negatively regulates the expression of ATG4C and ATG4D (17,18). miR-17 reduces ATG7 expression in glioblastoma cell lines (19). Furthermore, since the high-level autophagy in tumor cells following anticancer treatment is considered to be related with drug resistance (16), and Rothe et al demonstrated that miR-34a regulated the expres- 
sion of ATG4B in CML, and acted as a factor on regulating drug resistance (28), we focused on the regulation role of miR-34a on ATG4B in PCa. Notably, we found that ATG4B was the direct target of miR-34a in PCa.

$\mathrm{AMPK} / \mathrm{mTOR}$ is the essential regulator of cellular autophagy (29). We have proved the regulation of miR-34a on ATG4B, however, it is unclear whether the regulation effect is induced by the AMPK/mTOR pathway. We evaluated the expression of phosphorylated AMPK and mTOR after overexpression or silencing of miR-34a in PCa cells. According to its active role in autophagy $(30,31)$, p-AMPK was downregulated in miR-34a overexpressed PCa cells, followed by the upregulated p-mTOR, and in agreement with the inhibitory function of mTOR in autophagy $(32,33)$, upregulated p-mTOR, induced by miR-34a overexpression finally led to the decrease of autophagy-related proteins, including ATG4B, Beclin-1 and LC3B II/I. We found miR-34a downregulated autophagy-related proteins by the pathway of AMPK/mTOR.

In conclusion, we demonstrated that upregulation of miR-34a by transfection or demethylation resulted in the enhanced apoptosis and drug sensitivity in PCa cells. ATG4B, directly regulated by miR-34a through AMPK/mTOR, was involved in this process. Our research may supply a novel target for the future treatment on PCa chemoresistance.

\section{References}

1. Filipowicz W, Bhattacharyya SN and Sonenberg N: Mechanisms of post-transcriptional regulation by microRNAs: Are the answers in sight? Nat Rev Genet 9: 102-114, 2008.

2. Calin GA and Croce CM: MicroRNA signatures in human cancers. Nat Rev Cancer 6: 857-866, 2006.

3. Calin GA, Sevignani C, Dumitru CD, Hyslop T, Noch E, Yendamuri S, Shimizu M, Rattan S, Bullrich F, Negrini M, et al: Human microRNA genes are frequently located at fragile sites and genomic regions involved in cancers. Proc Natl Acad Sci USA 101: 2999-3004, 2004.

4. Jemal A, Siegel R, Ward E, Hao Y, Xu J and Thun MJ: Cancer statistics, 2009. CA Cancer J Clin 59: 225-249, 2009.

5. Shi XB, Xue L, Yang J, Ma AH, Zhao J, Xu M, Tepper CG, Evans CP, Kung HJ and deVere White RW: An androgenregulated miRNA suppresses Bak1 expression and induces androgen-independent growth of prostate cancer cells. Proc Natl Acad Sci USA 104: 19983-19988, 2007.

6. Lu Z, Liu M, Stribinskis V, Klinge CM, Ramos KS, Colburn NH and $\mathrm{Li}$ Y: MicroRNA-21 promotes cell transformation by targeting the programmed cell death 4 gene. Oncogene 27 . 4373-4379, 2008.

7. Sun R, Fu X, Li Y, Xie Y and Mao Y: Global gene expression analysis reveals reduced abundance of putative microRNA targets in human prostate tumours. BMC Genomics 10: 93, 2009.

8. Volinia S, Calin GA, Liu CG, Ambs S, Cimmino A, Petrocca F, Visone R, Iorio M, Roldo C, Ferracin M, et al: A microRNA expression signature of human solid tumors defines cancer gene targets. Proc Natl Acad Sci USA 103: 2257-2261, 2006.

9. Pang Y, Young CY and Yuan H: MicroRNAs and prostate cancer. Acta Biochim Biophys Sin 42: 363-369, 2010.

10. Hermeking H: p53 enters the microRNA world. Cancer Cell 12. 414-418, 2007.

11. Lodygin D, Tarasov V, Epanchintsev A, Berking C, Knyazeva T, Körner H, Knyazev P, Diebold J and Hermeking H: Inactivation of miR-34a by aberrant $\mathrm{CpG}$ methylation in multiple types of cancer. Cell Cycle 7: 2591-2600, 2008.

12. Fujita Y, Kojima K, Hamada N, Ohhashi R, Akao Y, Nozawa Y, Deguchi $\mathrm{T}$ and Ito $\mathrm{M}$ : Effects of miR-34a on cell growth and chemoresistance in prostate cancer PC 3 cells. Biochem Biophys Res Commun 377: 114-119, 2008.
13. Mizushima N: Autophagy: Process and function. Genes Dev 21: 2861-2873, 2007.

14. Choi AM, Ryter SW and Levine B: Autophagy in human health and disease. N Engl J Med 368: 651-662, 2013.

15. White E: Deconvoluting the context-dependent role for autophagy in cancer. Nat Rev Cancer 12: 401-410, 2012.

16. Yang ZJ, Chee CE, Huang S and Sinicrope FA: The role of autophagy in cancer: Therapeutic implications. Mol Cancer Ther 10: 1533-1541, 2011.

17. Korkmaz G, le Sage C, Tekirdag KA, Agami R and Gozuacik D: miR-376b controls starvation and mTOR inhibition-related autophagy by targeting ATG4C and BECN1. Autophagy 8: 165-176, 2012.

18. Frankel LB, Wen J, Lees M, Høyer-Hansen M, Farkas T, Krogh A, Jäättelä $\mathrm{M}$ and Lund $\mathrm{AH}$ : microRNA-101 is a potent inhibitor of autophagy. EMBO J 30: 4628-4641, 2011.

19. Comincini S, Allavena G, Palumbo S, Morini M, Durando F, Angeletti F, Pirtoli L and Miracco C: microRNA-17 regulates the expression of ATG7 and modulates the autophagy process, improving the sensitivity to temozolomide and low-dose ionizing radiation treatments in human glioblastoma cells. Cancer Biol Ther 14: 574-586, 2013.

20. Yang J, Chen D, He Y, Meléndez A, Feng Z, Hong Q, Bai X, Li Q, Cai G, Wang J, et al: MiR-34 modulates Caenorhabditis elegans lifespan via repressing the autophagy gene atg9. Age 35: 11-22, 2013.

21. Watahiki A, Wang Y, Morris J, Dennis K, O'Dwyer HM, Gleave M, Gout PW and Wang Y: MicroRNAs associated with metastatic prostate cancer. PLoS One 6: e24950, 2011

22. Bommer GT, Gerin I, Feng Y, Kaczorowski AJ, Kuick R, Love RE, Zhai Y, Giordano TJ, Qin ZS, Moore BB, et al: p53-mediated activation of miRNA34 candidate tumor-suppressor genes. Curr Biol 17: 1298-1307, 2007

23. Welch C, Chen Y and Stallings RL: MicroRNA-34a functions as a potential tumor suppressor by inducing apoptosis in neuroblastoma cells. Oncogene 26: 5017-5022, 2007.

24. Di Martino MT, Leone E, Amodio N, Foresta U, Lionetti M, Pitari MR, Cantafio ME, Gullà A, Conforti F, Morelli E, et al: Synthetic miR-34a mimics as a novel therapeutic agent for multiple myeloma: In vitro and in vivo evidence. Clin Cancer Res 18: 6260-6270, 2012.

25. Nalls D, Tang SN, Rodova M, Srivastava RK and Shankar S: Targeting epigenetic regulation of miR-34a for treatment of pancreatic cancer by inhibition of pancreatic cancer stem cells. PLoS One 6: e24099, 2011.

26. Li L, Xie X, Luo J, Liu M, Xi S, Guo J, Kong Y, Wu M, Gao J, Xie Z, et al: Targeted expression of miR-34a using the T-VISA system suppresses breast cancer cell growth and invasion. Mol Ther 20: 2326-2334, 2012.

27. Trang P, Wiggins JF, Daige CL, Cho C, Omotola M, Brown D, Weidhaas JB, Bader AG and Slack FJ: Systemic delivery of tumor suppressor microRNA mimics using a neutral lipid emulsion inhibits lung tumors in mice. Mol Ther 19: 1116-1122, 2011.

28. Rothe K, Lin H, Lin KB, Leung A, Wang HM, Malekesmaeili M, Brinkman RR, Forrest DL, Gorski SM and Jiang X: The core autophagy protein ATG4B is a potential biomarker and therapeutic target in CML stem/progenitor cells. Blood 123: 3622-3634, 2014

29. Fan X, Wang J, Hou J, Lin C, Bensoussan A, Chang D, Liu J and Wang B: Berberine alleviates ox-LDL induced inflammatory factors by up-regulation of autophagy via AMPK/mTOR signaling pathway. J Transl Med 13: 92, 2015.

30. Herrero-Martín G, Høyer-Hansen M, García-García C, Fumarola C, Farkas T, López-Rivas A and Jäättelä M: TAK1 activates AMPK-dependent cytoprotective autophagy in TRAILtreated epithelial cells. EMBO J 28: 677-685, 2009.

31. Matsui Y, Takagi H, Qu X, Abdellatif M, Sakoda H, Asano T, Levine B and Sadoshima J: Distinct roles of autophagy in the heart during ischemia and reperfusion: Roles of AMP-activated protein kinase and Beclin 1 in mediating autophagy. Circ Res 100: 914-922, 2007.

32. Sudarsanam S and Johnson DE: Functional consequences of mTOR inhibition. Curr Opin Drug Discov Devel 13: 31-40, 2010.

33. Jung $\mathrm{CH}$, Ro SH, Cao J, Otto NM and Kim DH: mTOR regulation of autophagy. FEBS Lett 584: 1287-1295, 2010. 